\title{
DROGAS ANTI-VIH: PASSADO, PRESENTE E PERSPECTIVAS FUTURAS
}

\author{
Marcus Vinícius Nora de Souza* \\ Fundação Oswaldo Cruz, Instituto de Tecnologia em Fármacos-Far Manguinhos, Rua Sizenando Nabuco, 100, 21041-250 \\ Rio de Janeiro - RJ \\ Mauro Vieira de Almeida \\ Departamento de Química, Instituto de Ciências Exatas, Universidade Federal de Juiz de Fora, 36038-330 Juiz de Fora - MG
}

Recebido em 20/6/02; aceito em 22/10/02

\begin{abstract}
DRUGS ANTI-HIV: PAST, PRESENT AND FUTURE PERSPECTIVES. Currently available anti-HIV drugs can be classified into three categories: nucleoside analogue reverse transcriptase inhibitors (NRTIs), non-nucleoside reverse transcriptase inhibitors (NNRTIs) and protease inhibitors (PIs). In addition to the reverse transcriptase (RT) and protease reaction, various other events in the HIV replicative cycle can be considered as potential targets for chemotherapeutic intervention: (1) viral adsorption, through binding to the viral envelope glycoprotein gp120; (2) viral entry, through blockage of the viral coreceptors CXCR4 and CCR5; (3) virus-cell fusion, through binding to the viral envelope glycoprotein gp 41; (4) viral assembly and disassembly through $\mathrm{NCp} 7$ zinc finger-targeted agents; (5) proviral DNA integration, through integrase inhibitors and (6) viral mRNA transcription, through inhibitors of the transcription (transactivation) process. Also, various new NRTIs, NNRTIs and PIs have been developed, possessing different improved characteristics.
\end{abstract}

Keywords: AIDS; new Anti-HIV drugs; replicative cycle.

\section{INTRODUÇÃO}

Os vírus estão envolvidos em uma grande variedade de doenças crônicas e degenerativas, sendo responsáveis por mais de $60 \%$ das doenças causadas no homem ${ }^{1}$. A luta contra as infecções virais é difícil, pois a replicação viral é um processo intracelular, estando intimamente relacionada ao metabolismo das células infectadas. Um dos vírus mais estudados hoje em dia é o chamado vírus da imunodeficiência humana (VIH) ou "Human Immunodeficiency Vírus" (HIV) 2,3 um vírus da família dos retrovírus (composto de ARN) ${ }^{4}$, capaz de parasitar o sistema imunológico do homem, levando a uma doença infecciosa conhecida como Síndrome da Imunodeficiência Adquirida (SIDA) ou "Acquired Immuno Deficiency Syndrome" (AIDS) $)^{5,6}$. O VIH é diferente dos outros vírus porque ataca e danifica o sistema imunológico, que é seu ponto principal de ataque no organismo humano. Um dos componentes do sistema imunológico são os linfócitos $\mathrm{T}$, que atacam diretamente o microorganismo invasor. Dentre os linfócitos T existe uma classe denominada T4 (T CD4+ ou T-auxiliadores), que tem um papel de extrema importância no desencadear da resposta imunitária e na coordenação dessa mesma resposta, sendo o alvo principal do vírus VIH. Este vírus, ao infectar os linfócitos T CD4+, conduz à falta de coordenação do sistema imunológico e à sua progressiva inoperância, acabando por estabelecer uma imunodeficiência ${ }^{7}$.

\section{CICLO DA REPLICAÇÃO VIRAL}

Para a obtenção de drogas eficazes no combate ao vírus VIH é extremamente importante conhecer como o vírus infecta o organismo (Figura 1$)^{8-10}$. A infecção de uma célula ocorre quando o vírus VIH se liga a um receptor celular, geralmente o T CD4+, por meio de sua proteína gp 120; o vírus então se funde à membrana celular e

*e-mail: mvndesouza@bol.com.br o conteúdo da cápside é liberado no citoplasma celular. A enzima do VIH, transcriptase reversa, catalisa a produção de uma cópia de ADN a partir do ARN do vírus VIH. A cópia de ADN de dupla hélice é então transportada ao núcleo celular onde uma segunda enzima do VIH, a integrase, catalisa a incorporação do ADN viral ao material genético do hospedeiro. A expressão subseqüente dos genes virais resulta na transcrição do ARN a partir do ADN do VIH e na tradução das proteínas virais. As proteínas virais recém-formadas são, no entanto, produzidas na forma de precursores de poliproteínas, longas unidades compostas de enzimas virais e proteínas estruturais ajunta-

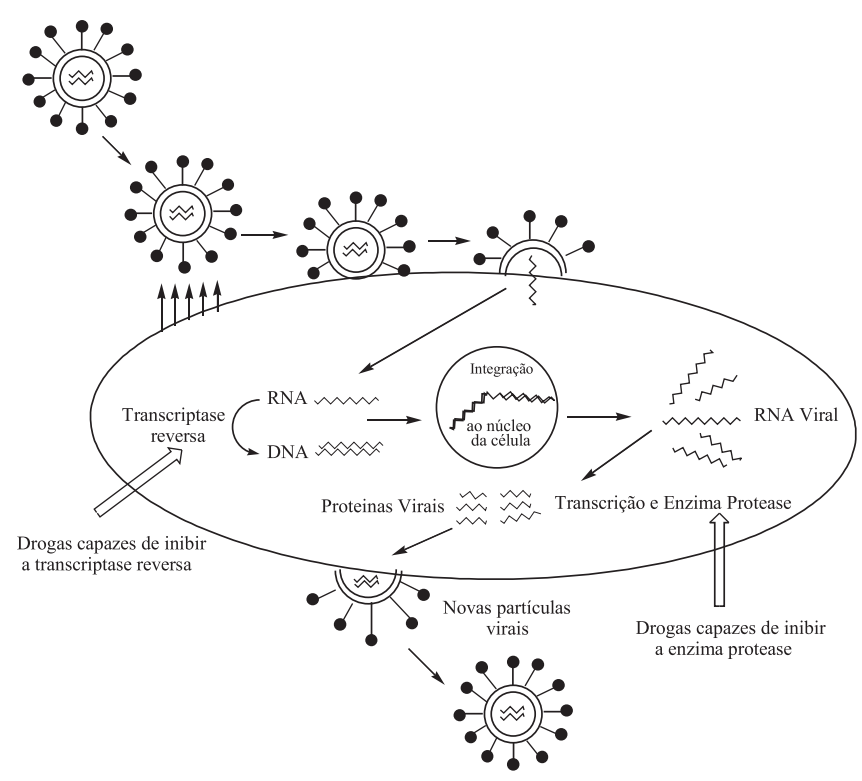

Figura 1. Esquema resumido do ciclo da replicação viral com as etapas em que atuam os medicamentos disponíveis no mercado 
das. As poliproteínas e o ARN viral movem-se para a superfície da célula onde ficam incorporados aos novos vírus que brotam na membrana celular, levando parte da mesma com eles para formar a camada externa viral. Os vírus recém-formados seriam, no entanto, não infectantes sem a ação de uma terceira e essencial enzima do VIH, a protease, que processa as poliproteínas virais em proteínas e enzimas estruturais funcionais.

\section{HISTÓRICO DAS DROGAS ANTI-VIH}

Em 1964, o AZT (3'-azido-2',3'-didesoxitimidina), também conhecido por azidotimidina, zidovudina ou retrovir (Figura 2), foi sintetizado pela primeira vez por Horwitz da Fundação contra o Câncer de Michigan ${ }^{11}$, apresentando atividade anticancerígina. No início da década de 70 sua atividade antiviral foi descrita pela primeira vez sendo, em 1985, o primeiro composto a apresentar atividade anti-VIH. Em 1986, o AZT foi aprovado pelo órgão norte-americano de controle sobre produtos farmacêuticos FDA ("Food and Drug Administration"), sendo comercializado pelos laboratórios Burroughs-Wellcome em $1987^{12}$.

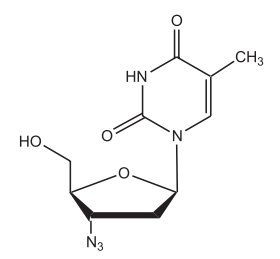

Figura 2. AZT (3'-azido-2',3'-didesoxitimidina), primeiro fármaco a apresentar atividade anti-VIH

A rota sintética utilizada foi a de Horwitz, sendo o primeiro método de preparação industrial do AZT (Esquema 1) ${ }^{11}$. Esta síntese tem como material de partida a Timidina $\mathbf{1}$, tendo sido realizada em seis etapas com um rendimento global de $30 \%$ e possuindo como etapa-chave a formação do intermediário cíclico 3.

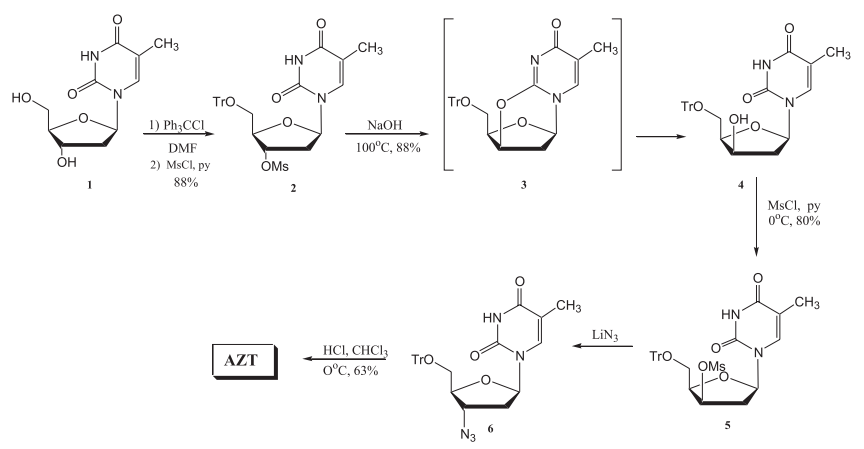

Esquema 1. Primeira rota sintética do AZT, realizada por Horwitz e utilizada em escala industrial pelos laboratórios Burroughs-Wellcome

Após a descoberta do AZT como anti-VIH, inúmeros análogos foram sintetizados com o objetivo de se obter fármacos mais eficazes. Devido a este amplo estudo estrutura-atividade (SAR="StructureActivity Relationship") foram identificados posições e grupos farmacofóricos e toxicofóricos (Figura 3) (3-15. $^{13}$.

Graças aos estudos estrutura-atividade anteriormente mencionados, em 1991 foram descobertos novos compostos análogos de
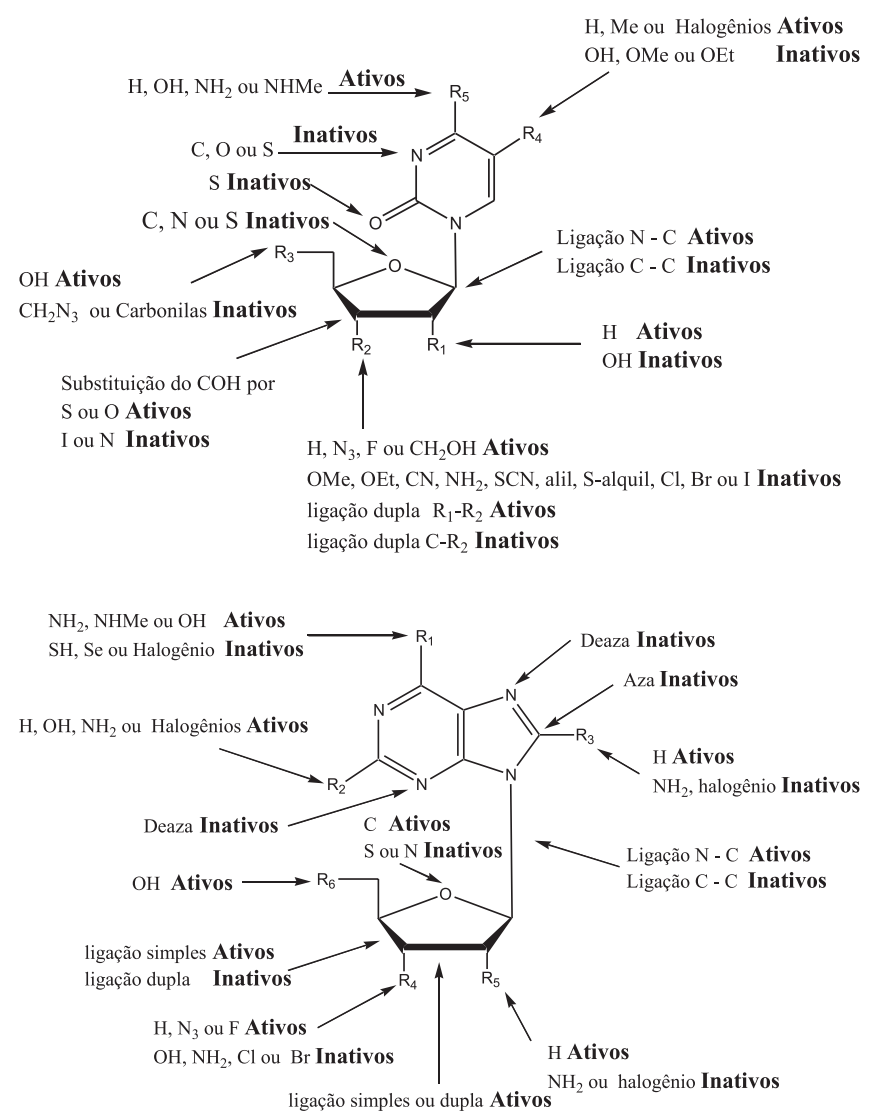

Figura 3. Relação estrutura-atividade anti-VIH em diferentes posições de nucleosídeos
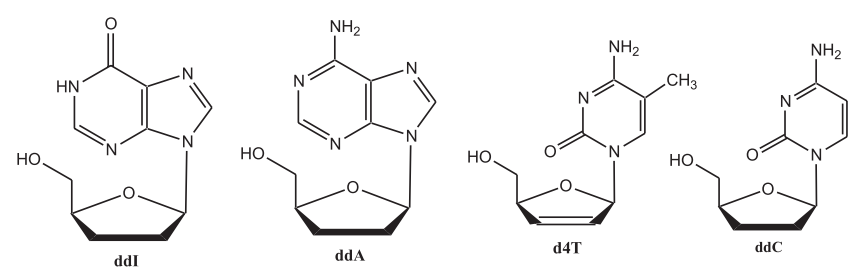

Figura 4. Análogos de nucleosídeos que apresentam atividade anti-VIH

nucleosídeos anti-VIH merecendo destaque os compostos ddI, ddA, d4T e o ddC (Figura 4) ${ }^{16-20}$.

\section{COMBINAÇÃO DE MEDICAMENTOS (COQUETEL DE DROGAS)}

Em 1996, na $11^{\text {a }}$ conferência internacional sobre a SIDA (Vancouver, Canadá), foi apresentada uma mistura conhecida como coquetel de drogas, que diminui em 100 vezes o ritmo de reprodução do vírus em relação à monoterapia até então empregada. Esta combinação de medicamentos utiliza drogas capazes de inibir diferentes etapas da replicação viral, sendo classificadas de acordo com as enzimas virais que inibem, dividindo-se em três categorias:

1) Inibidores de transcriptase reversa nucleosídeo-nucleotídeo (IsTRN)

2) Inibidores de transcriptase reversa não-nucleosídeo (IsTRNN)

3) Inibidores de protease (IsP) 


\section{MEDICAMENTOS ANTI-VIH DISPONÍVEIS NO MERCADO OU EM FASE DE TESTES CLÍNICOS}

\section{Inibidores de transcriptase reversa nucleosídeo-nucleotídeo (IsTRN)}

Atualmente, no mercado, existem sete medicamentos nucleosídeo-nucleotídeo capazes de inibir a enzima transcriptase reversa: AZT (zidovudina), d4T (stavudina), ddC (zalcitabina), 3TC (lamivudina), ddI (didadosina), ABC (abacavir) e tenofovir diisopropil (viread) (Figura 5) ${ }^{10,20-28}$.

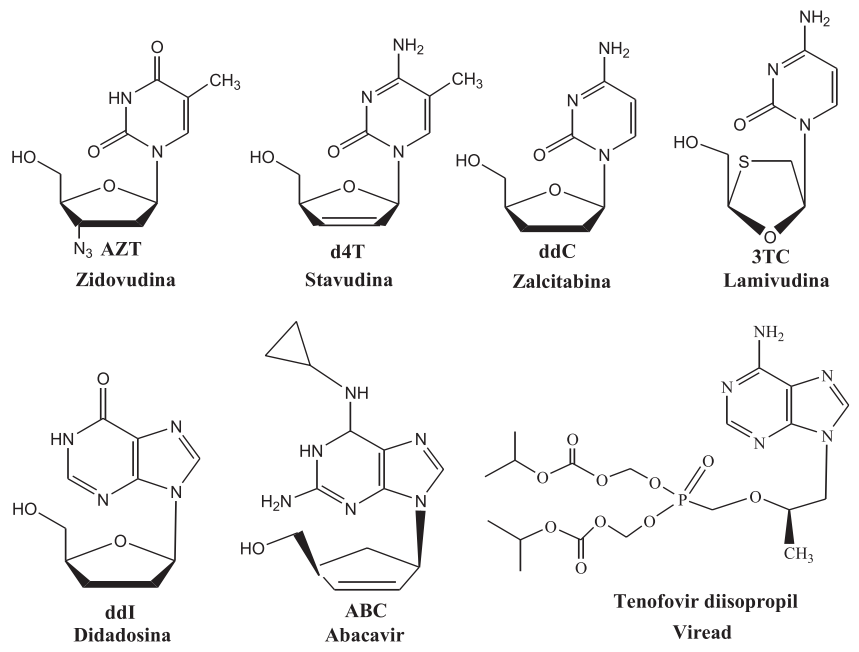

Figura 5. Medicamentos nucleosídeo-nucleotídeo disponíveis no mercado capazes de inibir a enzima transcriptase reversa

Para que os nucleosídeos tenham atividade antiviral contra a enzima transcriptase reversa, necessitam ser fosforilados pelo organismo pelas enzimas celulares chamadas de quinases, interrompendo assim a replicação viral (Figura 6) ${ }^{29,30}$.

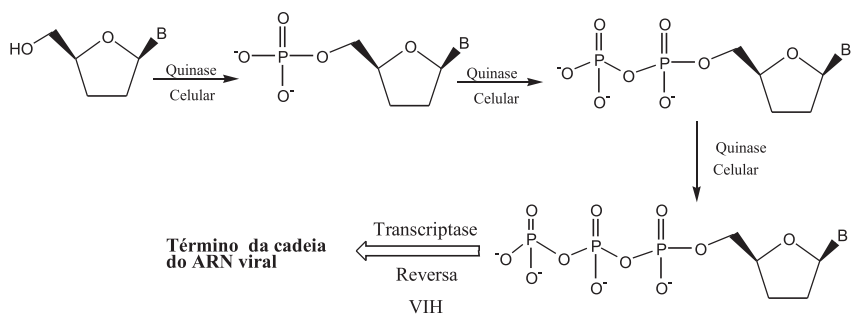

Figura 6. Fosforilação dos compostos nucleosídeos anti-VIH

Novas candidatas a drogas anti-VIH inibidoras da transcriptase reversa nucleosídeo-nucleotídeo (IsTRN)

Novos possíveis medicamentos anti-VIH inibidores da transcriptase reversa nucleosídeo-nucleotídeo (IsTRN) estão em fase de testes clínicos (Figura 7) ${ }^{10,20-25}$. O BCCH-10652 (dOTC) tem demonstrado atividade anti-VIH e, apesar de sua similaridade estrutural com o 3TC, tem se mostrado ativo contra o vírus VIH-1 resistente a este último medicamento. O (-) FTC está em fase de testes clínicos do tipo III para o vírus VIH e fase II para o vírus da hepatite tipo B (VHB), sendo considerado como um forte candidato para se incorporar ao coquetel anti-VIH, assim como no combate a infecções causadas pelo vírus da hepatite tipo B. O ciclosaligenil d4TMP e o $\mathrm{d} 4 \mathrm{~T}$ ariloxi-fosforamida possuem potente atividade anti-VIH contra o VIH-1 resistente, estando em fase de testes clínicos do tipo I. O bis(POM)-PMEA (adefovir dipivoxil) está em fase de testes III contra o VIH e o VHB. O fosfotriester bis(S-acetil-2-tioetil) do ddA [bis(SATE)ddAMP] tem se mostrado mil vezes mais potente contra o vírus VIH-1 que o ddA. O amdoxovir [DAPD, (-)- $\beta$-D-2,6diaminopurina dioxolano] tem se mostrado ativo contra vírus VIH-1 resistentes ao AZT e ao 3TC, estando em fase II de testes clínicos.

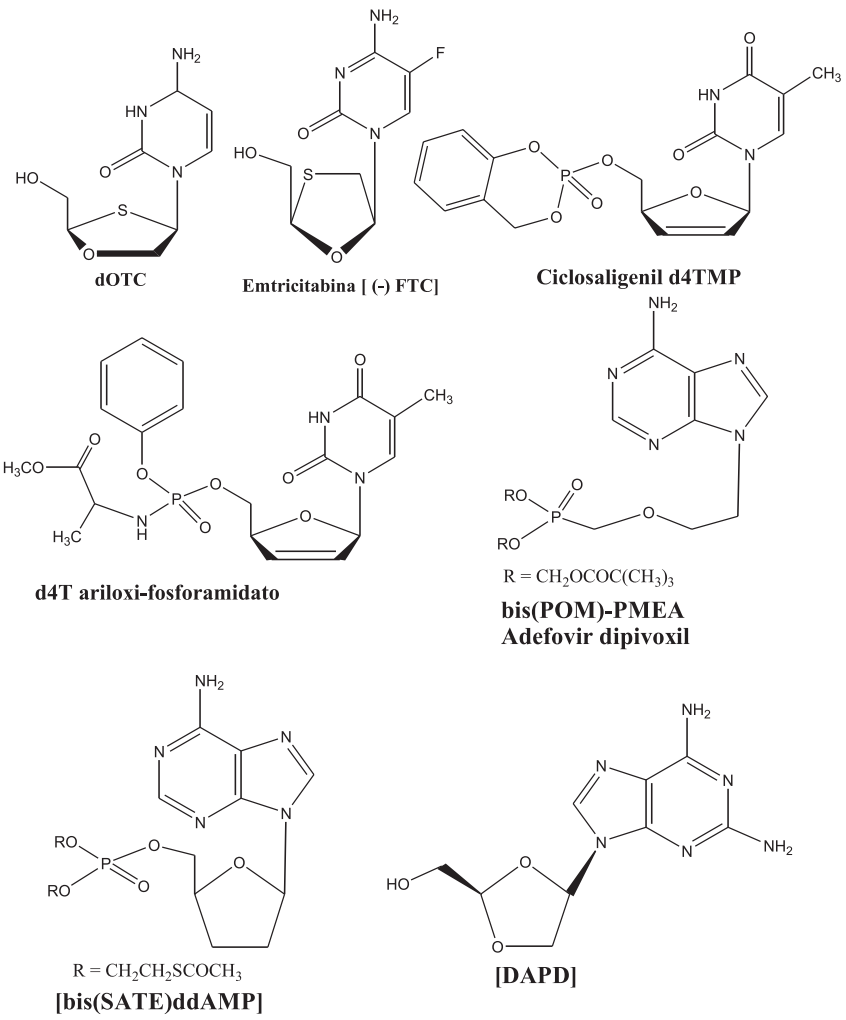

Figura 7. Compostos anti-VIH inibidores da transcriptase reversa nucleosídeo-nucleotídeo (IsTRN) em fase de testes clínicos

\section{Inibidores de transcriptase reversa não-nucleosídeos (IsTRNN)}

Atualmente, existem no mercado três medicamentos não nucleosídeo-nucleotídeo, capazes de inibir a enzima transcriptase reversa: nevirapina (viramune) $)^{31}$, efavirenz (sustiva) ${ }^{32,33}$ e delavirdina (rescriptor) (Figura 8) $)^{10,20-25}$
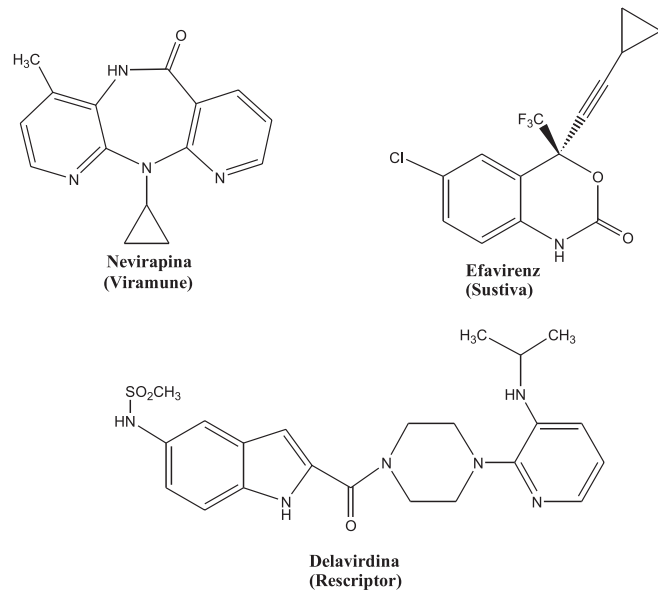

Figura 8. Medicamentos não nucleosídeo-nucleotídeo disponíveis no mercado capazes de inibir a enzima transcriptase reversa 


\section{Novas drogas potenciais anti-VIH não nucleosídeo-nucleotídeo (IsTRNN) inibidoras da transcriptase reversa}

Mais de 30 classes de diferentes compostos têm sido identificadas como inibidoras da transcriptase reversa não nucleosídeo-nucleotídeo (IsTRNN) ${ }^{34}$. Novos possíveis medicamentos anti-VIH do tipo IsTRNN estão em fase de testes clínicos (Figura 9) ${ }^{22}$. A Emivirina (MKC-442) está em fase de testes clínicos avançados do tipo III, podendo vir a ser um novo medicamento ${ }^{35}$. O SJ-3366 possui potente atividade anti-VIH-1, sendo capaz de inibir a replicação viral em concentrações abaixo de $1 \mathrm{nM}$ requerendo, entretanto, concentrações maiores no combate ao VIH-2 ${ }^{36}$. Os compostos DPC 083 e R165335 (TMC125) exibem, em concentrações nanomolares, potente atividade anti-VIH contra um amplo espectro de vírus VIH resistentes, sendo promissores candidatos a novas drogas contra este tipo de vírus ${ }^{22}$. O composto PNU-142721 ${ }^{37}$ está em fase de estudos clínicos e possui amplo espectro de atividade anti-VIH-1 e favoráveis propriedades farmacocinéticas. A (+)-Calanolida, isolada da árvore tropical Calophyllum lanigerum, é o único composto IsTRNN de procedência natural, estando em fase de testes clínicos do tipo $\mathrm{I}^{38-41}$. A Capravirina (AG1549) (2 $^{42}$ tem um perfil favorável como droga capaz de atuar na replicação de VIH resistentes, estando em fase de testes clínicos I e II. A tiocarboxanilida UC-781 possui uma potente atividade anti-VIH, sendo também capaz de restaurar a atividade antiviral do AZT contra vírus VIH resistentes ${ }^{34}$. A UC-781 tem sido reconhecida como capaz de reduzir a infecção do VIH-1 a níveis consideravelmente baixos, sendo um promissor medicamento para prevenir a transmissão do vírus VIH de pessoas infectadas para aquelas não infectadas ${ }^{34}$. A UC-781 poderia também ser uma candidata ideal como microbicida vaginal, se formulada em forma de gel $^{22}$.

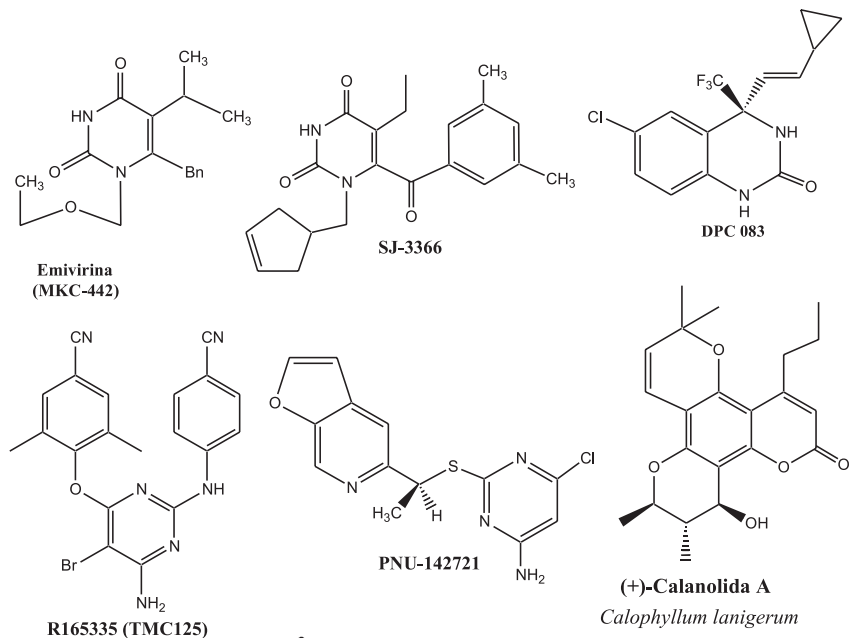<smiles>CC(C)=COc1cc(NC(=S)c2ccoc2C)ccc1Cl</smiles>

Figura 9. Compostos anti-VIH inibidores da transcriptase reversa não nucleosídeo-nucleotídeo (IsTRNN) em fase de testes clínicos

\section{Inibidores de protease (IsP)}

Atualmente, existem no mercado seis medicamentos capazes de inibir a enzima protease: saquinavir (fortovase), ritonavir (norvir), indinavir (crivixan), lopinavir, nelfinavir (viracept) e amprenavir (prozei) (Figura 10) ${ }^{10,20-25}$

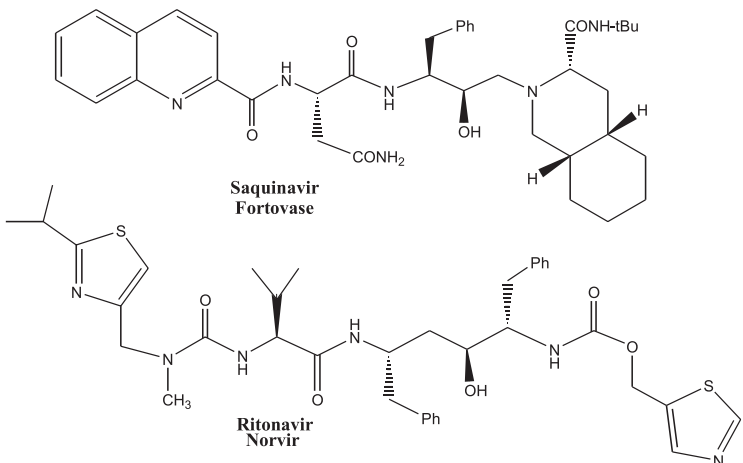<smiles>O=C(N[C@H]1c2ccccc2C[C@H]1O)[C@H](Cc1ccccc1)C[C@H](O)CN1CCN(Cc2cccnc2)C[C@H]1O</smiles><smiles>Cc1cccc(C)c1OC(=O)N[C@H](Cc1ccccc1)[C@H](O)C[C@H](Cc1ccccc1)NC(=O)[C@@H](C(C)C)N1CCCNC1=O</smiles><smiles>Cc1cccc(C)c1C(=O)N[C@H](CS)[C@H](O)CN1CC2CCCCC2CC1C(=O)NC(C)(C)C</smiles>

Figura 10. Medicamentos disponiveis no mercado capazes de inibir a enzima protease

\section{Novos candidatos a drogas anti-VIH inibidoras da enzima protease (IsP)}

Os medicamentos existentes no mercado atuam como inibidores peptídicos miméticos da protease do vírus VIH. Entretanto, estes vírus são capazes de adquirir resistência a esta classe de compostos. Devido a este problema, e na tentativa de se obter drogas mais eficazes, novos inibidores de protease não peptídicos têm sido desenvolvidos (Figura 11) ${ }^{22}$. A uréia cíclica mozenavir (DMP-450) possui substancial biodisponibilidade oral em todas as espécies observadas, incluindo o homem, estando em fase de testes clínicos I e II e apresentando boa atividade antiviral. O tripanavir (PNU-140690), uma sulfonamida contendo uma porção 5,6-diidro-4-hidroxipirona, possui baixa resistência cruzada e potente atividade anti-VIH-1 a vírus resistentes a drogas do tipo IsP. O atazanavir (BMS-232632) é um peptídeo mimético em fase de testes clínicos III (Figura 11) que apresenta favorável atividade anti-VIH-1 a vírus resistentes a drogas do tipo IsP, bem como favoráveis propriedades farmacocinéticas. 


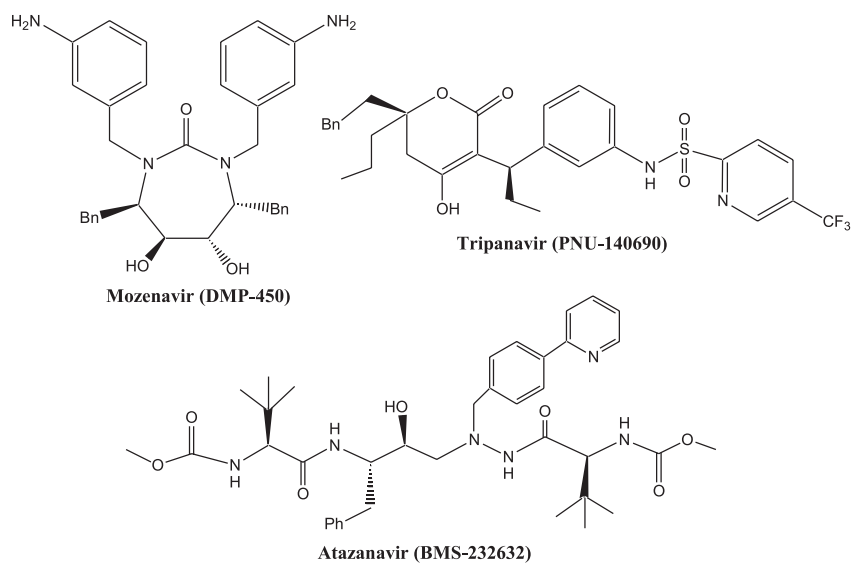

Figura 11. Compostos anti-VIH inibidores da enzima protease em fase de testes clínicos

\section{NOVAS ESTRATÉGIAS NO COMBATE A REPLICAÇÃO DO VIH}

Com objetivo de se obter novas drogas mais potentes, com melhores perfis farmacocinéticos, menores efeitos colaterais e com amplo espectro de atividade a diferentes vírus VIH resistentes, novas estratégias têm sido elaboradas (Figura 12). Estas estratégias baseiam-se na concepção de novos compostos capazes de inibir diferentes pontos da replicação viral dividindo-se em:

1) inibidores de fusão (IsF);

2) inibidores da proteína nucleocapsídica ( $\mathrm{NCp} 7)$;

3) inibidores da enzima integrase;

4) inibidores da enzima de transcrição.

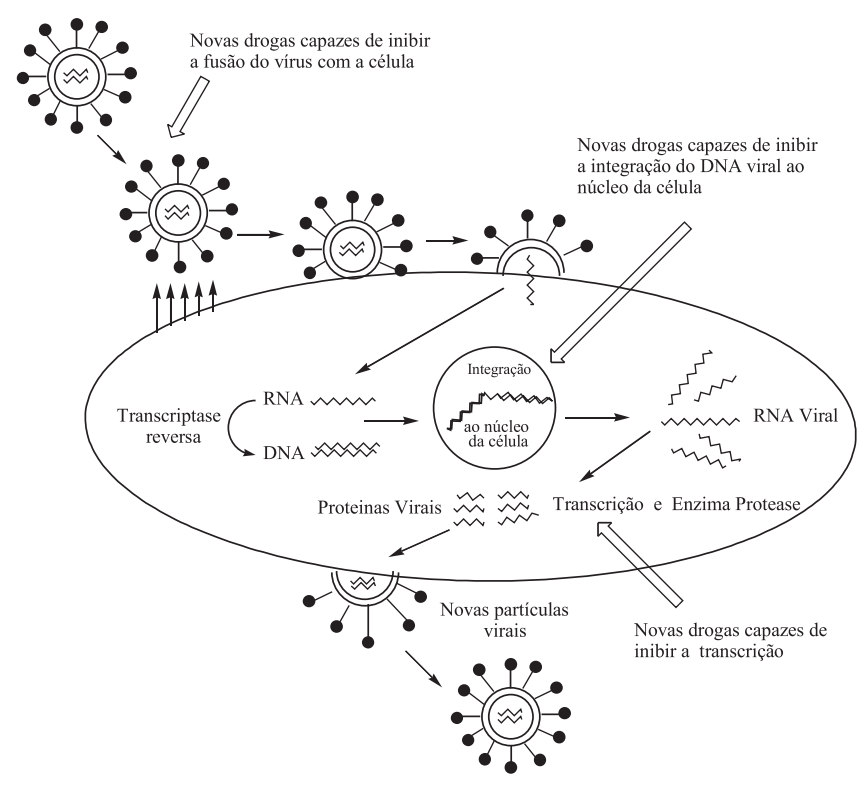

Figura 12. Novos alvos no combate à replicação do vírus VIH

\section{Inibidores de fusão (IsF)}

Os inibidores de fusão (IsF) representam uma nova abordagem na estratégia de combate à capacidade de replicação do VIH no orga- nismo. Para que o VIH complete o seu ciclo reprodutivo, necessita se fundir com um linfócito T, onde deposita a sua informação genética, dando origem a novos vírus. Enquanto os inibidores de protease (IsP) e da transcriptase reversa (IsTRN e IsTRNN) visam a interrupção do processo de replicação viral em uma fase em que o VIH já infectou a célula linfocitária alvo, os IsF foram concebidos de forma a impedir que o vírus consiga penetrar nos linfócitos e nem sequer inicie a infecção. Os compostos concebidos são capazes de bloquear três tipos de interação:

1) bloquear a interação da glicoproteína 120 (gp 120) com o CD4;

2) bloquear a interação da gp 120 com os co-receptores;

3) inibir as interações com a glicoproteína 41 (gp 41).

$\mathrm{Na}$ aproximação e fusão linfocitária, o VIH emprega dois complexos mediadores distribuídos na superfície da sua membrana externa: a gp 120 e a gp 41. Após a adesão, a gp 120 sofre uma modificação de sua conformação espacial, que permite o acoplamento do vírus VIH aos co-receptores CCR5 ou CXCR4 (receptores de quimiocinas). Isto permite que a gp 41 (glicoproteína transmembranar do envelope) se acople com a célula. Estes eventos seqüenciais fazem com que ocorra a aproximação das membranas da célula e do vírus, permitindo que o material genético viral entre na célula.

\section{Bloqueando a interação da gp 120 com o CD4}

Vários compostos polianiônicos têm sido descritos como capazes de bloquear a replicação do vírus VIH, interferindo na fusão do mesmo com a superfície da célula. Dentre eles podemos citar o cosalano e seus análogos contendo vários grupos carboxilatos (Figura 13$)^{43}$. Estes grupos hidrofílicos não penetram na membrana celular ou no envelope viral, impedindo assim a fusão do vírus com a célula (Figura 14) ${ }^{44}$.<smiles>CC(C)CCCC(C)[C@H]1CCC2C3CCC4C[C@H](CCC=C(c5cc(Cl)c(O)c(C(=O)O)c5)c5cc(Cl)c(O)c(C(=O)O)c5)CC[C@]4(C)C3CC[C@]21C</smiles><smiles>CC(C)CCCC(C)[C@H]1CCC2C3CCC4C[C@H](CCC=C(c5cc(Cl)c(OCc6ccc(C(=O)O)cc6)c(C(=O)O)c5)c5cc(Cl)c(OCc6ccc(C(=O)O)cc6)c(C(=O)O)c5)CC[C@]4(C)C3CC[C@]21C</smiles>

Figura 13. Cosalano e um análogo policarboxilado que possui potente atividade antiviral

Bloqueando a interação da gp 120 com os co-receptores

Para que o vírus VIH infecte a célula faz-se necessária a presença dos co-receptores chamados CCR5 e CXCR4, que são proteínas localizadas na superfície das células do sistema imunológico, permi- 


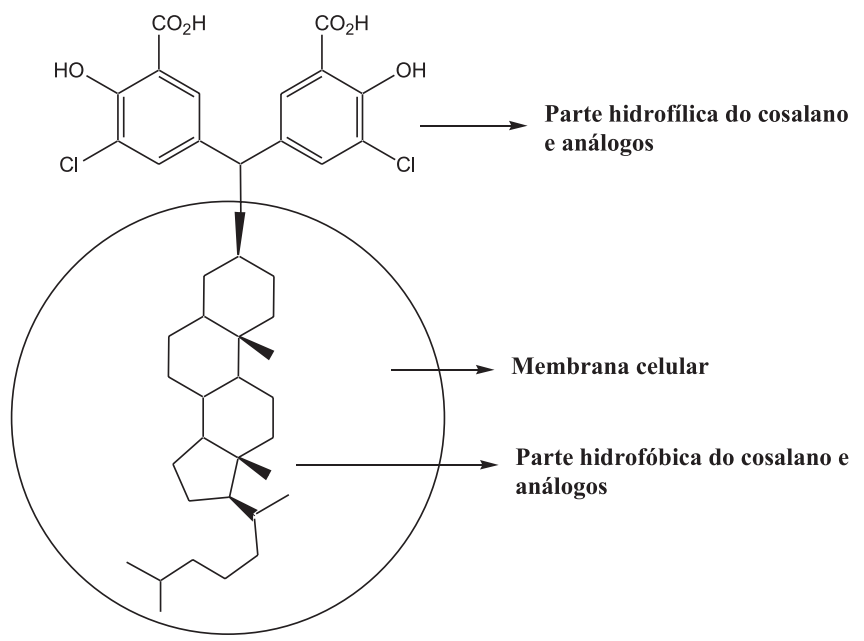

Figura 14. Modelo hipotético da atuação do cosalano e análogos na membrana celular e no envelope viral, impedindo a fusão do vírus com a célula hospedeira

tindo a fixação do vírus à superfície celular. Após a interação com a célula, a conformação do envelope viral se altera fazendo com que a gp 41 entre em contato com a superfície celular. Uma molécula capaz de impedir a participação destes co-receptores é o TAK-779 (Figura 15), sendo ativo em concentrações nanomolares ${ }^{45}$. Um outro composto, não peptídico, capaz de interagir com estes co-receptores é o biciclo AMD3100 (Figura 15) ${ }^{22}$, que se encontrava, em 2001, em testes clínicos em fase II. No entanto, os estudos clínicos foram interrompidos por causarem problemas cardíacos graves.
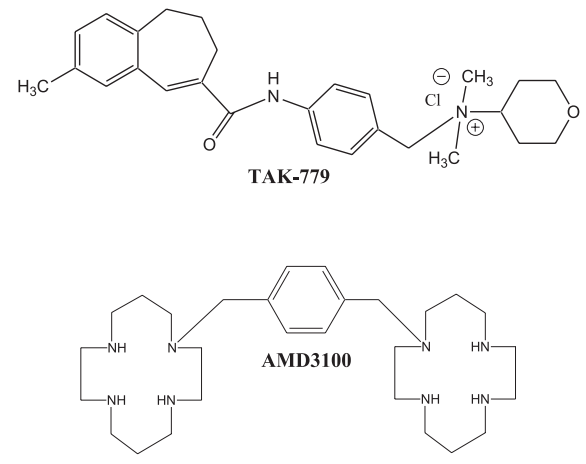

Figura 15. Moléculas capazes de inibir a interação da gp 120 com os coreceptores CCR5 e CXCR4

\section{Inibindo interações com a gp 41}

Uma outra estratégia para combater a replicação viral é impedir que a glicoproteína gp 41 entre em contato com a superfície celular, interferindo no rearranjo estrutural requerido para o VIH invadir a célula. O composto RPR 103611 é o único composto de baixa massa molar não peptídico capaz de interagir com a gp 41, bloqueando a infecção viral em concentrações inferiores a 10nM (Figura 16) ${ }^{22}$. Um outro medicamento promissor é o T-2022, um peptídeo sintético composto de 36 aminoácidos. Este novo fármaco foi concebido pelas multinacionais Roche Holding AG (Suíça) e Trimeris Inc. (USA), que planejam lançá-lo no mercado em 2003, pois seus testes clínicos de fase III já estão concluídos. O T- $1249^{22}$, um peptídeo sintético de 39 aminoácidos, representa uma geração mais recente e os estudos ainda estão na fase inicial de ensaios clínicos.

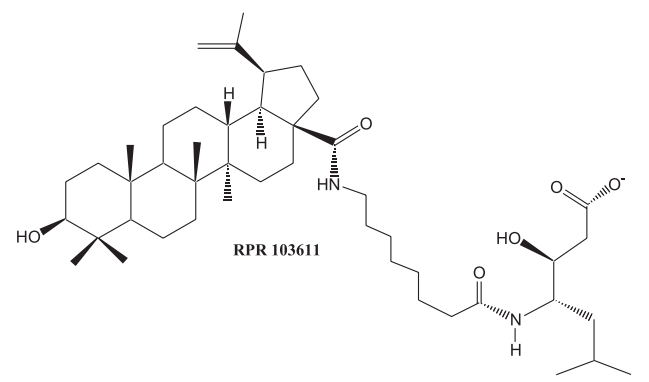

Figura 16. Molécula capaz de impedir a interação da gp 41 no processo de fusão com a célula hospedeira

Proteína nucleocapsídica (NCp7)

A proteína nucleocapsídica (NCp7) é uma proteína essencial em diferentes etapas da replicação viral, sendo importante na etapa que envolve a enzima trancriptase reversa, participando da anelação do ARN. O ADA (azodicarbonamida, Figura 17) é um composto em fase de testes clínicos II e capaz de tornar inativa esta proteína, pela complexação com seus átomos de zinco, impedindo a replicação $\operatorname{viral}^{22,46}$.

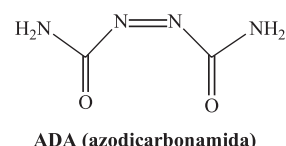

Figura 17. Molécula capaz de impedir a atuação da proteína nucleocapsídica $\mathrm{NCp} 7$ no processo de replicação viral

\section{Inibidores de integrase}

A enzima integrase é fundamental no processo de replicação viral, sendo responsável pela integração do ADN viral ao cromossoma hospedeiro, permitindo assim a continuação do ciclo da replicação viral. O ácido-L-quicórico (Figura 18) é capaz de inibir a atividade da enzima integrase de diferentes tipos de VIH resistentes ${ }^{47}$. Recentemente, o dicetoácido L-731,988 (Figura 18) apresentou também atividade capaz de inibir esta enzima ${ }^{48}$.<smiles>O=C(/C=C/c1ccc(O)c(O)c1)OC(=O)[C@@H](OC(=O)C(=O)O)[C@H](OC(=O)/C=C/c1ccc(O)c(O)c1)C(=O)O</smiles>

Figura 18. Moléculas capazes de impedir a atuação da enzima integrase no processo de replicação viral

\section{Inibidores da transcrição}

O processo da transcrição consiste na síntese de ARN, sendo realizado por um complexo enzimático cuja enzima chave é a ARN polimerase, capaz de produzir as proteínas virais na forma de precursores de poliproteínas, longas unidades compostas de enzimas virais e proteínas estruturais ajuntadas. As fluorquinolonas são uma classe de compostos sintéticos com potente atividade antimicrobiana. Atualmente, esta classe de compostos também tem sido descrita como capazes de interferir no processo de transcrição viral, impedindo desta forma a replicação. A fluorquinolona K-37 (Figura 19) ${ }^{49}$ tem apre- 
sentado bons resultados na inibição desta enzima. A temacrazina ${ }^{50} \mathrm{e}$ o flavopiridol ${ }^{51}$ são outros compostos capazes de inibirem esta enzima de transcrição, ainda que em células cronicamente infectadas (Figura 19).<smiles>Cn1cc(C(=O)O)c(=O)c2cc(F)c(N3CCC(c4ccccc4)CC3)c(C(F)(F)F)c21</smiles><smiles></smiles><smiles>CN1CCC(c2c(O)cc(O)c3c(=O)cc(-c4ccccc4Cl)oc23)CC1</smiles>

Figura 19. Moléculas capazes de impedir a atuação da enzima de transcrição no processo de replicação viral

\section{CONCLUSÃO}

Graças ao conhecimento adquirido nestes 20 anos de epidemia, consegue-se hoje transformar uma infecção agudamente letal em uma doença crônica e controlável. Apesar das dificuldades, o tratamento da SIDA através da quimioterapia avançou muito nos últimos anos, proporcionando uma vida mais digna e produtiva para as pessoas soropositivas. No entanto, a busca por drogas mais potentes a diferentes tipos de VIH resistentes, com baixos efeitos colaterais e custos reduzidos, tem sido objeto de intensa pesquisa e continua a ser uma área muito promissora.

\section{REFERÊNCIAS}

1. Korolkovas, A.; Essentials of Medicinal Chemistry, $2^{\text {nd }}$ ed., Wiley: New York, 1988.

2. Barre-Sinoussi, F.; Cherman, J. C.; Rey, F.; Nugeyre, M. T.; Charmaret, S.; Gruest, J.; Dauguet, C.; Axler-Blin, C.; Brun-Vezinet, F.; Rouzioux, C.; Rosenbaum, W.; Montagnier, L.; Science 1983, 220, 868.

3. Johnson, R.; Chenoweth, D.; J. Biol. Chem. 1989, 260, 7161.

4. Gupta, C.; Costello, C.; Khorana, H.; Proc. Natl. Acad. Sci. U.S.A. 1979, $76,2595$.

5. Heyward, W.; Curran, J.; Pour la Science 1988, 134, 48.

6. Grmek, M. D.; La Recherche 1991, 234, 985.

7. http://www.ordembiologos/Biologias/N1.hmtl, acessada em Junho 2002.

8. De Clercq, E.; La Recherche 1986, 29, 1561.

9. Schild, G. C.; Minor, P. D.; Lancet 1990, 335, 1081.

10. De Clercq, E.; Med. Mal. Infect. 2000, 30, 421.

11. Horwitz, J. P.; Chua, J.; Noel, M.; J. Org. Chem. 1964, 29, 2076.

12. Yarchan, R.; Mitsuya, H.; Broder, S.; Matthews, T.; Bolognesi, D.; Pour La Science 1988, 134, 94.

13. Naor, M.; Litterst, C.; McGowan, J.; Antiviral Res. 1990, 14, 125.

14. Herdewijn, P.; De Clercq, E.; Design of Anti-Aids Drugs; Ed. Elsevier Science: Amsterdan, 1990, p. 141-171.

15. Goulaouic-Dubois, C.; Tese de Doutorado; Universidade Paris XI, França, 1994.
16. Mitsuya, H.; Broder, S.; Proc. Natl. Acad. Sci. U.S.A. 1986, 83, 1911.

17. Yarchoan, R.; Mitsuya, H.; Thomas, R. V.; Pluda, J. M.; Hartman, N. R.; Perno, C. F.; Marczyk, K. S.; Allain, J. P.; Jonhs, D. G.; Broder, S.; Science 1989, 245, 412

18. Lin, T. S.; Schinazi, R. F.; Prusoff, W. H.; Biochem. Pharmacol. 1987, 36, 2713.

19. Mitsuya, H.; Broder, S.; Nature 1987, 325, 773.

20. Tavel, J. A.; Miller, K. D.; Masur, H.; Clin. Infect. Dis. 1999, 28, 643.

21. De Clercq, E.; Antiviral Res. 1989, 12, 1.

22. De Clercq, E.; Biochim. Biophys. Acta 2002, 62127.

23. De Clercq, E.; J. Clin. Virol. 2001, 22, 73.

24. Li, X.; Chan, K.; Adv. Drug Delivery Rev. 1999, 39, 81.

25. De Clercq, E.; Int. J. Antimicrob. Agents 1997, 9, 21.

26. Huff, J. R.; Bioorg. Med. Chem. 1999, 7, 3667.

27. Schultze, L. M.; Chapman, H. H.; Dubree, J. P.; Jones, R. J.; Kent, K. M.; Lee, T. T.; Louie, M. S.; Postich, M. J.; Prisbe, E. J.; Rodhloff, J. C.; Yu, R. H.; Tetrahedron Lett. 1998, 39, 1853.

28. De Clercq, E.; J. Med. Chem. 1995, 38, 2491.

29. Clair, S.; Richards, C. A.; Spector, T.; Weinhold, K. J.; Miller, W. H.; Langlois, A. J.; Furman, P. A.; Antimicrob. Agents Chemother. 1987, 31, 1972.

30. Huang, P.; Farquhar, D.; Plunkett, W.; J. Biol. Chem. 1990, 265, 11914; Ikemoto, T.; Nishiguchi, A.; Mitsudera, H.; Wakimasu, M.; Tomimatsu, K.; Tetrahedron 2001, 57, 1525

31. Grozinger, K. G.; Fuchs, V.; Hargrave, S.; Mauldin, J.; Vitous, C.; J. Heterocycl. Chem. 1995, 32, 259.

32. Cocuzza, A. J.; Chidester, D. R.; Cordova, B. C.; Klabe, R. M.; Jeffrey, S.; Diamond, S.; Weigelt, C. A.; Ko, S. S.; Bacheler, L. T.; EricksonViitanen, S. K.; Rodgers, J. D.; Bioorg. Med. Chem. Lett. 2001, 11, 1389.

33. Cocuzza, A. J.; Chidester, D. R.; Cordova, B. C.; Jeffrey, S.; Parsons, R. L.; Ko, S. S.; Bacheler, L. T.; Erickson-Viitanen, S; Trainor, G. L.; Bioorg. Med. Chem. Lett. 2001, 11, 1177.

34. De Clercq, E.; Antiviral Res. 1998, 38, 153.

35. Ren, J.; Esnouf, R. M.; Hopkins, A. L.; Warren, J.; Balzarini, J.; Stuart, D. I.; Stammers, D. K.; Biochemistry 1998, 37, 14394.

36. Buckheit Jr., R. W.; Watson, K.; Fliakas-Boltz, V.; Russell, J.; Loftus, T. L.; Osterlin, M. C.; Turpin, J. A.; Pallansch, L. A.; White, E. L.; Lee, J. W.; Lee, S. H.; Oh, J. W.; Kwon, H. S.; Chung, S. G.; Cho, E. H.; Antimicrob. Agents Chemother. 2001, 45, 393.

37. Wishka, D. G.; Graber, D. R.; Kopta, L. A.; Olmsted, R. A.; Friis, J. M.; Hosley, J. D.; Adams, W. J.; Seest, E. P.; Castle, T. M.; Dolak, L. A.; Keiser B. J.; Yagi, Y.; Jeganathan, A.; Schlachter, S. T.; Murphy, M. J.; Cleek, G. J.; Nugent, R. A.; Poppe, S. M.; Swaney, S. M.; Han, F.; Watt, W.; White, W. L.; Poel, T. J.; Thomas, R. C.; Voorman, R. L.; Stefanski, K. J.; Stehle, R. G.; Tarpley W. G.; Morris, J.; J. Med. Chem. 1998, 41, 1357.

38. Tanaka, T.; Kumamoto, T.; Ishikawa, T.; Tetrahedron Lett. 2000, 41, 10229.

39. Fuller, R. W.; Bokesch, H. R.; Gustafson, K. R.; McKeene, T. C.; Cardelina II, J. H.; McMahon, J. B.; Cragg, G. M.; Soejarto, D. D.; Boyd, M. R.; Bioorg. Med. Chem. Lett. 1994, 16, 1961.

40. Fox, M. E.; Lennon, I. C.; Meek, G.; Tetrahedron Lett. 2002, 43, 2899.

41. Kucherenko, A.; Flavin, M. T.; Boulanger, W. A.; Khilevich, A.; Shone, R. L.; Rizzo, J. D.; Sheinkman A.; K.; Xu, Z. Q.; Tetrahedron Lett. 1995, 36,5475 .

42. Brown, W. M.; Curr. Opin. Anti-Infect. Invest. Drugs 2000, 2, 286.

43. Golebiewski, W. M.; Bader, J. P.; Cushman, M.; Bioorg. Med. Chem. Lett. 1993, 3, 1739

44. Kannan, A.; De Clercq, E.; Pannecouque, C.; Witvrouw, M.; Hartman, T. L.; Turpin, J. A.; Bruckheit Jr., R. W.; Cushman, M.; Tetrahedron 2001, 57,9385 .

45. Ikemoto, T.; Nishiguchi, A.; Mitsudera, H.; Wakimasu, M.; Tomimatsu, K.; Tetrahedron 2001, 57, 1525

46. Vandevelde, M.; Witvrouw, M.; Schmidt, J. C.; Sprecher, S.; De Clerq, E.; Tassignon, J. P.; AIDS Res. Hum. Retroviruses 1996, 12, 567.

47. King, P. J.; Robinson Jr., W. E.; J. Virol. 1998, 72, 8420.

48. Hazuda, D. J.; Felock, P.; Witmer, M.; Wolfe, A.; Stillmock, K.; Grobler, J. A.; Espeseth, A.; Gabryelski, L.; Schleif, W.; Blau, C.; Miller, M. D.; Science 2000, 287, 646.

49. Okamoto, H.; Cujec, T. P.; Okamoto, M.; Peterlin, B. M.; Baba, M.; Okamoto, T.; Virology 2000, 272, 402.

50. Turpin, J. A.; Bruckheit Jr., R. W.; Derse, D.; Hollingshead, M.; Williamson, K.; Palamone, C.; Osterling, M. C.; Hill, S. A.; Grahan, L.; Schaeffer, C. A.; Bu, M.; Huang, M.; Cholody, W. M.; Michejda, C. J.; Rice, W. G.; Antimicrob. Agents Chemother 1998, 42, 487.

51. Murti, K. K.; Dubay, M.; McClure, C.; Brizuela, L.; Boisclair, M. D.; Worland, P. J.; Mansuri, M. M.; Pal; Bioorg. Med. Chem. Lett. 2000, 10, 1037. 